\title{
A Novel Enhanced Isolation Microstrip Dual-polarization Patch
} Antenna

\author{
Long Jin $^{1 \mathrm{a})}$, Zhibin $\mathrm{He}^{1}$, Kewei Qian ${ }^{1}$, Shiwei Yuan ${ }^{1}$, Jiuyang Xiao ${ }^{1}$, Yao Sun ${ }^{1}$, and Yangmiao Lin ${ }^{1}$
}

Abstract A novel dual-polarization edge-fed microstrip patch antenna was designed in this letter. In order to increase the isolation between the two ports with different polarizations and reduce the working modes affected by the feed line, two-section continuous current strips were separated from the metal ground plane. The measured result shows that the antenna has a port-to-port isolation better than $28.9 \mathrm{~dB}$ from $5.725 \mathrm{GHz}$ to $5.875 \mathrm{GHz}$, and particularly better than $32.6 \mathrm{~dB}$ at $5.8 \mathrm{GHz}$, which is improved more than $12 \mathrm{~dB}$ compared with traditional antennas. Besides, a dual-polarization excitationcan be realized within the single patch antenna for a single layer dielectric structure.

key words: dual-polarization, microstrip antenna, isolation, patch antenna Classification: Microwave and millimeter wave devices, circuits, and hardware

\section{Introduction}

Dual-polarization antennas improve the system performance because of polarization diversity or frequency reuse, such as reducing multipath fading, improving channel capacity and measurement accuracy. The $5.725-5.875 \mathrm{GHz}$ is the Industrial, Scientific, and Medical (ISM) band, which is used as the common frequency band for point-to-point or point-tomultipoint spread spectrum communication system, highspeed wireless LAN, broadband wireless access system, motion sensors, Bluetooth technology equipment and automatic vehicle identification system. In the modern mobile communication system dual-polarization antennas have received much attention. They are widely used in cellular communication, Multiple-Input Multiple-Output (MIMO) systems, radar systems, and Worldwide Interoperability for Microwave Access (WIMAX). The dual-polarization microstrip patch antenna has the characteristics of light weight, small size, low cost and low profile, so it is convenient to integrate in the structure of building windows, solar panels and display screens. In order to meet these requirements, many dual-polarization microstrip patch antenna designs have been proposed [1]-[23].

\footnotetext{
${ }^{1}$ Research Institute Electronic Science and Technology, University of Electronic Science and Technology of China,Chengdu, Sichuan, 610054 P.R.China

a) jinlong@uestc.edu.cn
}

DOI: $10.1587 /$ elex.18.20210249

Received June 07, 2021

Accepted July 01, 2021

Publicized July 09, 2021
However, when dual polarization is realized on microstrip patch antenna, the isolation between ports should be considered, which will seriously affect the performance of the antenna when the isolation between ports is poor. In order to achieve high isolation, various types of studies have been reported. For the reported design in [24], [25], by using the aperture coupling feed, the current discontinuity is reduced, the polarization purity is improved, and the high isolation of microstrip patch antenna is realized. But the structure of multilayer substrate is not only unfavorable to fabricate, but also increasing the volume and cost of antenna. In [26], [27], isolation is improved by adding parasitic patches around the same plane as the antenna, but the added parasitic patches in addition to the cost increase, the specific antenna shape needs a specific parasitic patch shape, which is not conducive to the design of the array antenna. A vertical metal wall is used to converge the surface current in the position of the vertical metal wall to achieve high isolation, but the addition of the metal wall makes the profile increase and is not conducive to the fabrication [28].

The low cost and easy to fabrication are good at commercial realization. So for dual-polarization antenna, it is a meaningful task. In this letter, dual-polarization double inset-fed microstrip patch antenna will be adopted, the novel idea is that continuous current strip is added to connect two sides of feed line. Compared with the double-fed model before continuous current strips are added, the proposed antenna greatly reduces mutual coupling between the two ports.

\section{Antenna configuration}

Fig.1 shows a printed circuit board(PCB) of the top and bottom of the novel enhanced isolation microstrip dualpolarized patch antenna. Table I shows the design parameters of the front of the proposed antenna, and table II shows the design parameters of continuous current strips. The proposed antenna is a square patch fed by inset microstrip line. The system is achieved on FR4 epoxy with dielectric constant $\left(\varepsilon_{r}=4.4\right)$, thickness $(h=1 \mathrm{~mm})$, and loss tangent $(\delta=$ $0.02)$ with overall size $(11.8 \mathrm{~mm} \times 11.8 \mathrm{~mm} \times 1 \mathrm{~mm})$, the patch antenna and the floor are both made up with copper (thickness is $0.017 \mathrm{~mm}$ ).

It is noted that two sides of the feed port are separated by the inset microstrip feed line in the antenna, and the 


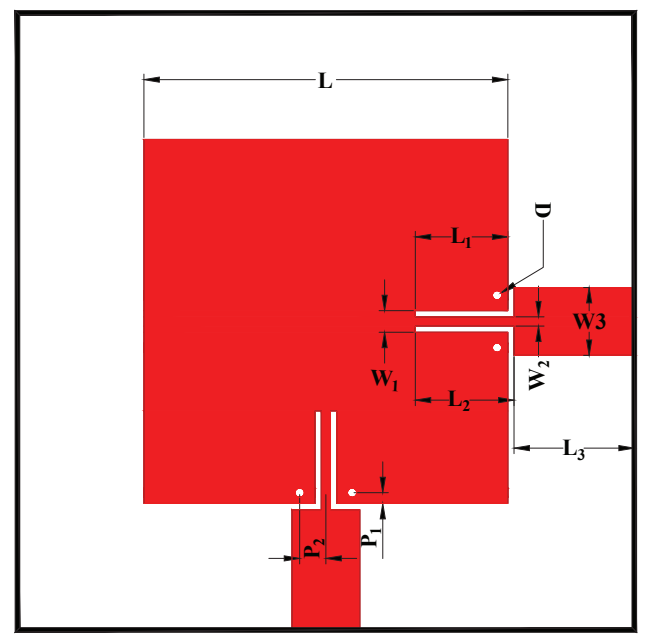

(a)

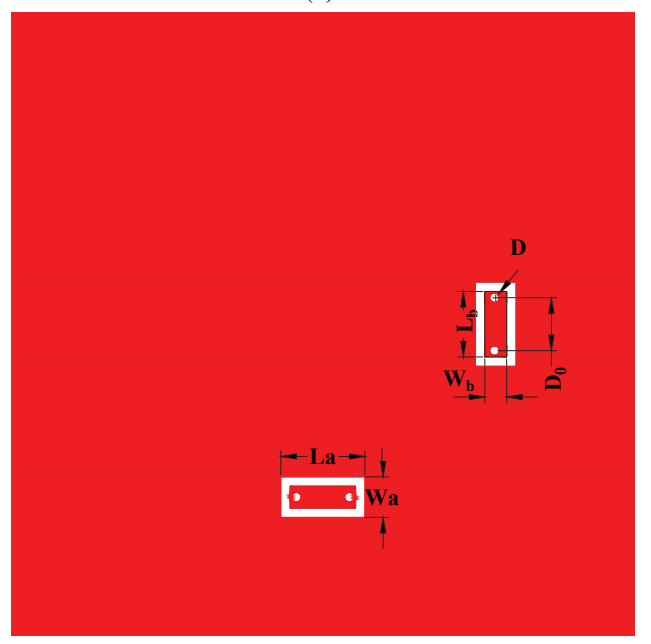

(b)

Fig. 1: Proposed dual-polarization antenna structure. (a)Front view. (b)Back view.

continuous current strip is connected to the two sides. The proposed antenna is improved from the original dual-port dual-polarization microstrip antenna with orthogonal feed, adding a continuous current strip to connect two sides of one feed line. As can be seen from Fig.1, a continuous current strip consists of two via holes and a slender strip paralleling to the floor surface. The material of via holes and slender strips is copper. Two via holes are connected to a slender strip through medium substrate, and finally the connection with antenna is realized by via holes. The parameters of the proposed antenna can be seen from TABLE I and TABLE

Table I: PARAMETERS OF THE RADIATING PATCH

\begin{tabular}{cccc}
\hline \hline Parameter & Value $(\mathrm{mm})$ & Parameter & Value $(\mathrm{mm})$ \\
\hline$L$ & 11.8 & $D$ & 0.3 \\
$L_{1}$ & 3.0 & $W_{1}$ & 0.7 \\
$L_{2}$ & 3.2 & $W_{2}$ & 0.3 \\
$L_{3}$ & 3.9 & $W_{3}$ & 2.2 \\
$P_{1}$ & 0.35 & $P_{2}$ & 0.85 \\
\hline
\end{tabular}

Table II: PARAMETERS OF THE CONTINUOUS CURRENT STRIP

\begin{tabular}{cccc}
\hline \hline Parameter & Value $(\mathrm{mm})$ & Parameter & Value $(\mathrm{mm})$ \\
\hline$L_{a}$ & 3.0 & $W_{b}$ & 0.7 \\
$L_{b}$ & 2.5 & $D_{0}$ & 1.7 \\
$W_{a}$ & 1.2 & $D$ & 0.3 \\
\hline
\end{tabular}

II.

The material, size and shape of the two inset feed ports and the two continuous current strips are the same. HFSS (HighFrequency Structure Simulator) will be used to simulate and optimize the antenna structure.

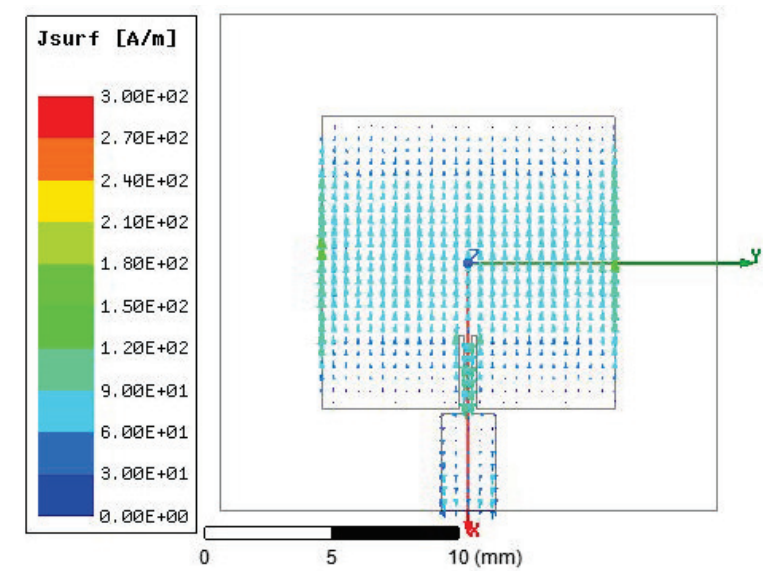

(a)

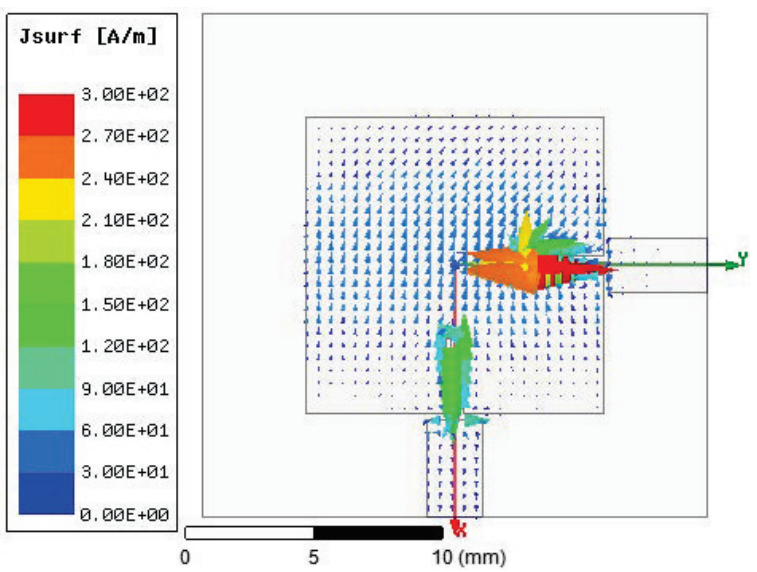

(b)

Fig. 2: the surface current distribution of antennas. (a)Single inset-fed microstrip antenna. (b)Double inset-fed microstrip antenna at $x=L / 2, y=0$ feed.

\section{Antenna design}

When microstrip antennas are excited at whether microstrip line feed or coaxial feed line port, more than one mode is usually excited. Microstrip antennas are half-wavelength structures and are operated at the fundamental resonant mode TM01 or TM10 in general. For the square microstrip patch antenna, the cavity model is used to judge the current distri- 
bution when the patch antenna excites the mode TM10 and TM01 [29]. The square antenna with the length $L$ uses microstrip feed line, and the width is $d$, which is the effective width of a uniform strip of z-directed source current of $1 \mathrm{~A}$ [30]. It is supposed that total current is $1 \mathrm{~A}$ and the thickness is $h$. If feeding current of the microstrip line is shown in equation (1) below, the surface current can be obtained when the working mode of which is TM10.

$$
J_{z}=\left\{\begin{array}{cl}
\frac{1}{d h}, & x=\frac{L}{2}, \frac{-W_{2}}{2}<y<\frac{W_{2}}{2} \\
0, & \text { other }
\end{array}\right.
$$

Where $J_{z}$ is the volume current fed for the microstrip line. The distribution of surface current of the patch can be obtained according to the boundary conditions

$$
\mathbf{J}_{\text {surf }}=-\hat{i}_{x} j \frac{B_{10}}{\omega \mu_{0}}\left(\frac{\pi}{L}\right) \cos \frac{\pi x}{L}
$$

Where $B_{10}$ is the complex number when point feed is known. From the (1)(2), it can be concluded that:

In mode TM10(edge-fed along a straight line parallel to the $\mathrm{x}$-axis or feed along $x=L / 2, y=0$ ), a sinusoidal distribution of surface current flows in the $x$ direction. When $x=-L / 2$ or $x=L / 2$, the surface current is 0 , and when $x=0$, The surface current is the maximum value. When the both two modes need to work on the square patch antenna to realize dual-polarization, the inset microstrip feed line can be carried out around $x=L / 2, y=0$ and $x=0, y=L / 2$, respectively. However, when working mode is mode TM10 which excited by microstrip feed line at $x=L / 2, y=0$, another microstrip feed line at $x=0, y=L / 2$ result in the current discontinuity where the current $J_{x}$ is the maximum. Similarly, the current discontinuity of mode TM10 is the same circumstance. Current path changes in the double inset structure and results in a poor isolation between the ports. As shown in Fig.2(a) and (b), the added inset-ded line cause the the current discontinuity and the current flows around the inset-fed line the current flows out the antenna. In order to solve the problem caused by the realization of dual polarization antenna, the two sides of the inset structure are connected by continuous current strip. After adding continuous current strip, the current flowing along the embedded structure will flow along the continuous current strip, which reducing the current winding and converging on the port, as shown in Fig.3. Coupling between two ports is reduced.

Flow direction of the part of the surface current is changed by the continuous current strip, which also makes the phase of this part of surface current change. The proposed double fed antenna with the continuous current strip makes the electrical length a little bit more longer than that of the single-fed antennas, but shorter than that of the double fed antennas, so the addition of continuous current strip can make a various center frequency. As shown in Fig.4, the impedance matching band is from $5.77 \mathrm{GHz}$ to $5.94 \mathrm{GHz}$. As shown in Fig.5, the isolation of the traditional double

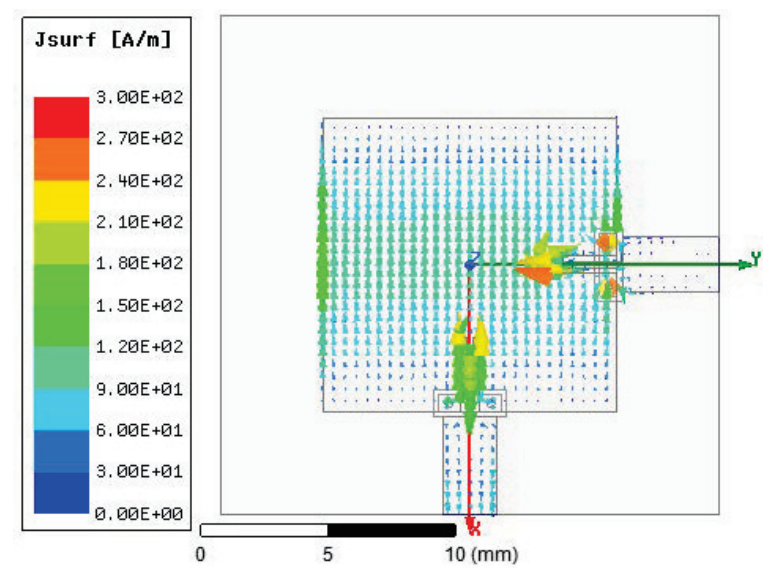

Fig. 3: the surface current distribution of proposed antenna feeding at $x=L / 2, y=0$.

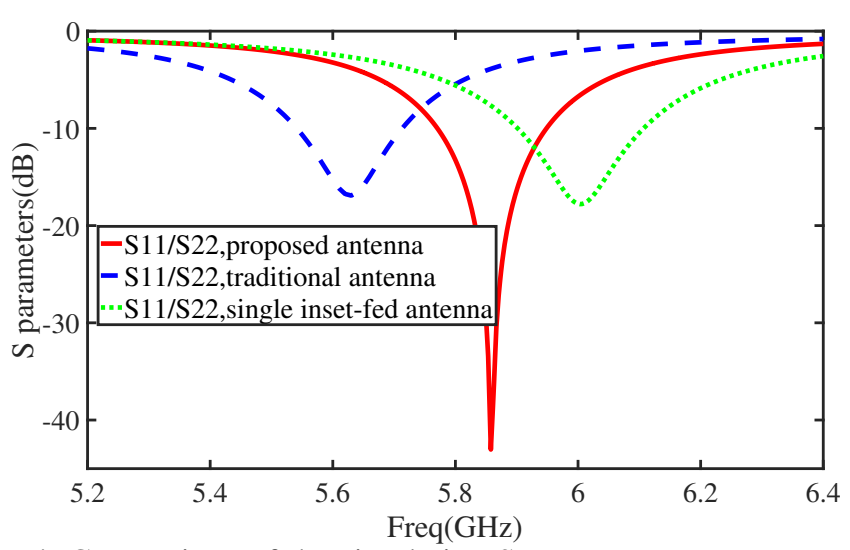

Fig. 4: Comparison of the simulation S-parameters among proposed antenna,traditional antenna,and single inset-fed microstrip antenna.

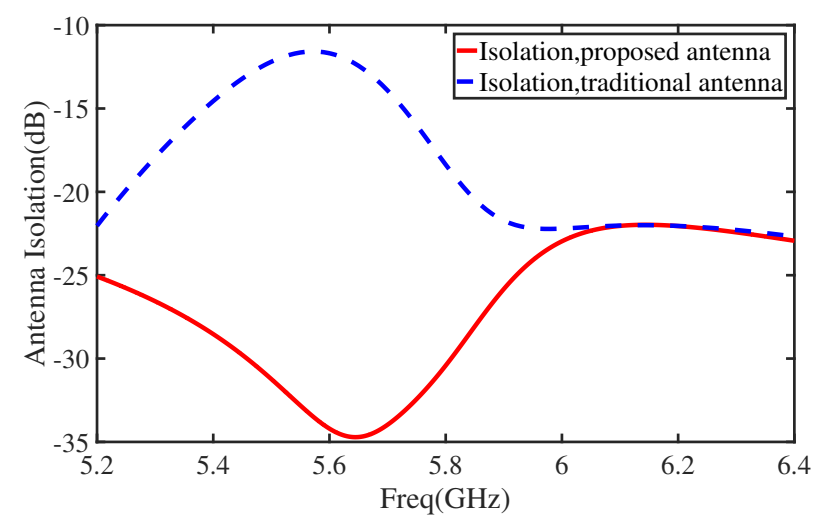

Fig. 5: Comparison of the simulated isolation between proposed antenna and its conventional counterpart without continuous current strips.

inset-fed microstrip antenna is $18.36 \mathrm{~dB}$ at $5.8 \mathrm{GHz}$, while the isolation of the proposed antenna is $30.4 \mathrm{~dB}$, which has improved approximately $12 \mathrm{~dB}$. Besides, isolation better than $27 \mathrm{~dB}$ covering $5.725 \mathrm{GHz}$ to $5.875 \mathrm{GHz}$ has been achieved for the proposed antenna. In Fig.6, when $f_{0}=5.8 \mathrm{GHz}$, the 
radiation patterns of the proposed antenna excited on $x=$ $L / 2, y=0$ are shown at E-plane and H-plane respectively. The symmetry pattern shows that when $f_{0}=5.8 \mathrm{GHz}$, and the excitation is at another port,the radiation patterns of E-plane and H-plane are the same with those excited on $x=L / 2, y=0$, as shown in Fig.6.

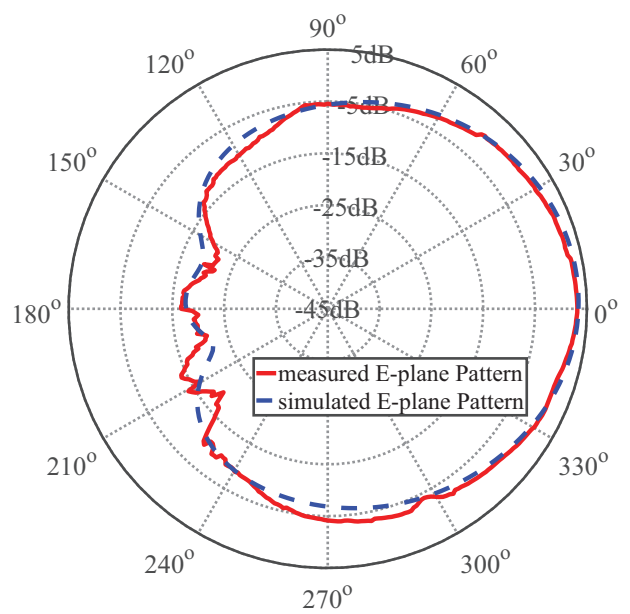

(a)

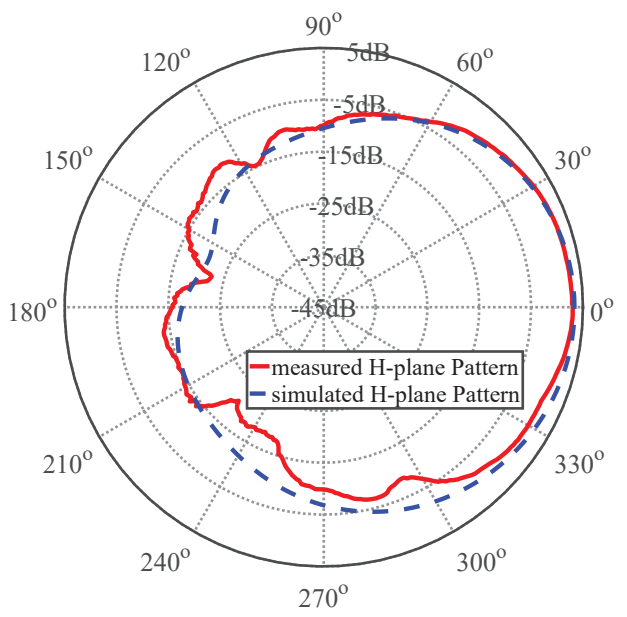

(b)

Fig. 6: Simulated and measured radiation patterns of the proposed antenna excitation on the $x=L / 2, y=0$ at $5.8 \mathrm{GHz}$. (a)E-plane. (b)H-planes

\section{Experimental measurements}

The proposed antenna was fabricated and tested, and the prototypes are shown in Fig.7. Fig.8 shows the simulated and measured return loss and isolation of the proposed antenna. The antenna exhibits a simulated $170 \mathrm{MHz}$ matching bandwidth for the band from $5.77 \mathrm{GHz}$ to $5.94 \mathrm{GHz}$, while the measured matching bandwidth is about $150 \mathrm{MHz}$, which is from $5.8 \mathrm{GHz}$ to $5.95 \mathrm{GHz}$. This antenna is designed for indoor mobile sensors. It works in the upper of the ISM band to avoid interference with $5.8 \mathrm{GHz}$ WiFi.

The antenna also exhibits a simulated $30.4 \mathrm{~dB}$ and a mea-

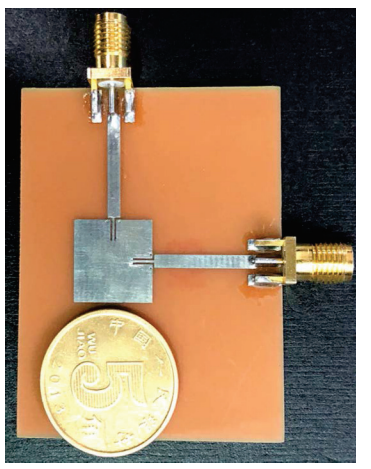

(a)

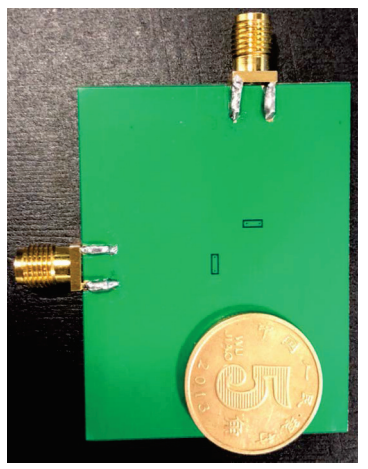

(b)
Fig. 7: Photograghs of (a)the front view of proposed antenna. (b)the back view of proposed antenna.

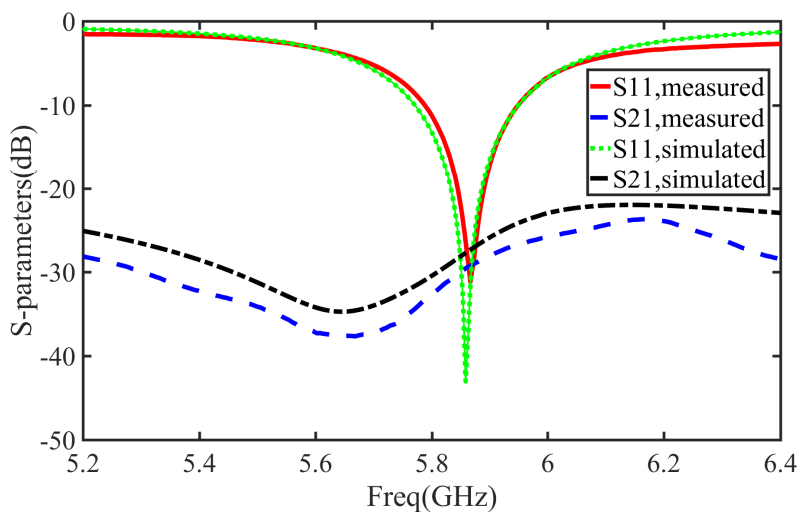

Fig. 8: Simulated and measured return loss and isolation for the proposed antenna.

sured $32.6 \mathrm{~dB}$ isolation at 5.8GHz. In fig.6(a) and fig.6(b), the simulated and measured radiation patterns of the proposed antenna excited on the $x=L / 2, y=0$ at $5.8 \mathrm{GHz}$ are shown at E-plane and $\mathrm{H}$-plane respectively.

Table III compares the performance of the proposed antenna with some already-published results. Compared to [24],[27],[28], the proposed antenna is feasible to fabricate for its single-layer and simple structure. Also, the low cost and single material in substrate is the advantages of proposed antenna. As mentioned in [27], integrated strips at the two port can improve isolation. However, the size of antenna using the continuous current strips is not expanded. The low gain of the proposed antenna is due to the use of FR4, a low-cost dielectric material with high loss.

\section{Conclusion}

In this letter, a low-profile, low-cost and dual-polarization microstrip patch antenna with enhanced isolation proposed. The simulation and measurement show that the proposed antenna has a good impedance matching at the frequency of $5.8 \mathrm{GHz}$, and a high isolation of $32.6 \mathrm{~dB}$ is achieved at the meantime. By introducing two additional continuous current strips, the perturbation of the working modes by microstrip feed lines is effectively reduced. The coupling between the 
IEICE Electronics Express, Vol.VV, No.NN, 1-6

Table III: COMPARISON OF THE PROPOSED AND REFERENCE ANTENNAS

\begin{tabular}{|c|c|c|c|c|}
\hline Reference & {$[24]$} & {$[27]$} & {$[28]$} & proposed \\
\hline size $\left(\lambda_{0}^{3}\right)$ & $1.40 \times 1.40 \times 0.12$ & $0.45 \times 0.45 \times 0.02$ & $0.38 \times 0.38 \times 0.16$ & $0.23 \times 0.23 \times 0.02$ \\
\hline structure & the quasi-cross slot & $\begin{array}{c}\text { integrated strips at the } \\
\text { ports }\end{array}$ & with vertical metal wall & $\begin{array}{c}\text { the continuous current } \\
\text { strips }\end{array}$ \\
\hline dielectric layer & multilayer & singlelayer & multilayer & singlelayer \\
\hline $\begin{array}{c}\text { relative dielectric } \\
\text { constant }\end{array}$ & $2.65,2.2,1$ & 1.7 & $4.4,1$ & 4.4 \\
\hline BW(MHz) & 200 & 150 & 500 & 150 \\
\hline isolation(dB) & $>50$ & $>20$ & 930 & 26 \\
\hline gain(dBi) & 9.6 & About 7.8 & 3.2 & 3.6 \\
\hline $\begin{array}{c}\text { center frequancy } \\
(\mathrm{GHz})\end{array}$ & 3.5 & 2.425 & 3.55 & 5.875 \\
\hline
\end{tabular}

two modes is reduced, so as to improve the isolation of dual-polarization antenna. The test results show that the isolation can reach $32.6 \mathrm{~dB}$ at $5.8 \mathrm{GHz}$, which is better than $14 \mathrm{~dB}$ without continuous current strip's. In the meanwhile, a single-layer dielectric structure instead of multi-lay dielectric structure is easier to process and realize lower cost.

\section{References}

[1] X. Zhao, J. Jin, J. Cheng and L. Liang, "A Wideband Dual-Polarized Array Antenna With Conical Elements for Wi-Fi/WiMAX Application," in IEEE Antennas and Wireless Propagation Letters, vol. 13, pp. 1609-1612, 2014, doi: 10.1109/LAWP.2014.2346781.

[2] S. Mathew, R. Anitha, U. Deepak, C. K. Aanandan, P. Mohanan and K. Vasudevan, "A Compact TriBand Dual-Polarized Corner-Truncated Sectoral Patch Antenna," in IEEE Transactions on Antennas and Propagation, vol. 63, no. 12, pp. 5842-5845, Dec. 2015, doi: 10.1109/TAP.2015.2479216.

[3] C. -X. Mao et al., "X/Ka-Band Dual-Polarized Digital Beamforming Synthetic Aperture Radar," in IEEE Transactions on Microwave Theory and Techniques, vol. 65, no. 11, pp. 4400-4407, Nov. 2017, doi: 10.1109/TMTT.2017.2690435.

[4] Z. Qamar, J. L. Salazar-Cerreno and N. Aboserwal, "An Ultra-Wide Band Radome for High-Performance and DualPolarized Radar and Communication Systems," in IEEE Access, vol. 8, pp. 199369-199381, 2020, doi: 10.1109/ACCESS.2020.3032881.

[5] J. Hershberger, T. Pratt and R. Kossler, "Implementations of Coherent Software-Defined Dual-Polarized Radars," in IEEE Transactions on Microwave Theory and Techniques, vol. 65, no. 5, pp. 1673-1681, May 2017, doi: 10.1109/TMTT.2017.2672550.

[6] S. H. Yueh, R. Kwok, Shu-Hsiang Lou and Wu-Yang Tsai, "Sea ice identification using dual-polarized Ku-band scatterometer data," in IEEE Transactions on Geoscience and Remote Sensing, vol. 35, no. 3, pp. 560-569, May 1997, doi: $10.1109 / 36.581968$.

[7] H. Zhai, K. Zhang, S. Yang and D. Feng, "A Low-Profile Dual-Band Dual-Polarized Antenna With an AMC Surface for WLAN Applications," in IEEE Antennas and Wireless Propagation Letters, vol. 16, pp. 2692-2695, 2017. doi: 10.1109/LAWP.2017.2741465

[8] W. C. Zheng, L. Zhang, Q. X. Li and Y. Leng, "Dual-Band Dual-Polarized Compact Bowtie Antenna Array for Anti-
Interference MIMO WLAN," in IEEE Transactions on Antennas and Propagation, vol. 62, no. 1, pp. 237-246, Jan. 2014. doi: 10.1109/TAP.2013.2287287

[9] J. Liang, J. Hong, J. Zhao and W. Wu, "Dual-Band Dual-Polarized Compact Log-Periodic Dipole Array for MIMO WLAN Applications," in IEEE Antennas and Wireless Propagation Letters, vol. 14, pp. 751-754, 2015. doi: 10.1109/LAWP.2014.2378772

[10] E. A. Soliman, M. S. Ibrahim and A. K. Abdelmageed, "Dual-polarized omnidirectional planar slot antenna for WLAN applications," in IEEE Transactions on Antennas and Propagation, vol. 53, no. 9, pp. 3093-3097, Sept. 2005. doi: 10.1109/TAP.2005.854544

[11] Y. Zhang, Y. Zhang, D. Li, K. Liu and Y. Fan, "DualPolarized Band-Notched Antenna Without Extra Circuit for 2.4/5 GHz WLAN Applications," in IEEE Access, vol. 7, pp. 84890-84896, 2019. doi: 10.1109/ACCESS.2019.2924494

[12] Tzung-Wern Chiou and Kin-Lu Wong, "A compact dualband dual-polarized patch antenna for $900 / 1800-\mathrm{MHz}$ cellular systems," in IEEE Transactions on Antennas and Propagation, vol. 51, no. 8, pp. 1936-1940, Aug. 2003. doi: 10.1109/TAP.2003.814728

[13] B. Feng, C. Zhu, J. Cheng, C. Sim and X. Wen, "A Dual-Wideband Dual-Polarized Magneto-Electric Dipole Antenna With Dual Wide Beamwidths for 5G MIMO Microcell Applications," in IEEE Access, vol. 7, pp. 43346-43355, 2019. doi: 10.1109/ACCESS.2019.2906882

[14] X. Dai, Z. Wang, C. Liang, X. Chen and L. Wang, "Multiband and Dual-Polarized Omnidirectional Antenna for 2G/3G/LTE Application," in IEEE Antennas and Wireless Propagation Letters, vol. 12, pp. 1492-1495, 2013. doi: 10.1109/LAWP.2013.2289743

[15] B. Feng, J. Lai and C. Sim, "A Building Block Assembly Dualband Dual-Polarized Antenna With Dual Wide Beamwidths for $5 \mathrm{G}$ Microcell Applications," in IEEE Access, vol. 8, pp. 123359-123368, 2020. doi: 10.1109/ACCESS.2020.3006074

[16] S. Costanzo, F. Venneri, A. Borgia and G. D. Massa, "Dual-Band Dual-Linear Polarization Reflectarray for mmWaves/5G Applications," in IEEE Access, vol. 8, pp. 78183-78192, 2020. doi: 10.1109/ACCESS.2020.2989581

[17] H. Li, Y. Li, L. Chang, W. Sun, X. Qin and H. Wang, "A Wideband Dual-Polarized Endfire Antenna Array With Overlapped Apertures and Small Clearance for 5G Millimeter-Wave Applications," in IEEE Transactions on Antennas and Propagation, vol. 69, no. 2, pp. 815-824, Feb. 2021, doi: 10.1109/TAP.2020.3016512. 
[18] C. Ding, L. Liu and K. -M. Luk, "An Optically Transparent Dual-Polarized Stacked Patch Antenna With MetalMesh Films," in IEEE Antennas and Wireless Propagation Letters, vol. 18, no. 10, pp. 1981-1985, Oct. 2019, doi: 10.1109/LAWP.2019.2935694.

[19] H. Huang, X. Li and Y. Liu, "A Low-Profile, Dual-Polarized Patch Antenna for 5G MIMO Application," in IEEE Transactions on Antennas and Propagation, vol. 67, no. 2, pp. 1275-1279, Feb. 2019, doi: 10.1109/TAP.2018.2880098.

[20] H. Saeidi-Manesh and G. Zhang, "High-Isolation, Low Cross-Polarization, Dual- Polarization, Hybrid Feed Microstrip Patch Array Antenna for MPAR Application," in IEEE Transactions on Antennas and Propagation, vol. 66, no. 5, pp. 2326-2332, May 2018, doi: 10.1109/TAP.2018.2811780.

[21] K. Li, T. Dong and Z. Xia, "A Broadband Shared-Aperture L/S/X-Band Dual-Polarized Antenna for SAR Applications," in IEEE Access, vol. 7, pp. 51417-51425, 2019, doi: 10.1109/ACCESS.2019.2911965.

[22] Y. Zhang, Z. Song, W. Hong and R. Mittra, "Wideband high-gain $\pm 45^{\circ}$ dual-polarised stacked patch antenna array for Ku-band back-haul services," in IET Microwaves, Antennas \& Propagation, vol. 14, no. 1, pp. 53-59, 812020. https://doi.org/10.1049/iet-map.2019.0272

[23] C. Deng, B. Yektakhah and K. Sarabandi, "Series-Fed DualPolarized Single-Layer Linear Patch Array With High Polarization Purity," in IEEE Antennas and Wireless Propagation Letters, vol. 18 , no. 9 , pp. 1746-1750, Sept. 2019, doi: 10.1109/LAWP.2019.2929226.

[24] J. Lu, Z. Kuai, X. Zhu and N. Zhang, "A High-Isolation DualPolarization Microstrip Patch Antenna With Quasi-CrossShaped Coupling Slot," in IEEE Transactions on Antennas and Propagation, vol. 59, no. 7, pp. 2713-2717, July 2011, doi: 10.1109/TAP.2011.2152333.

[25] H. Li, L. Kang, F. Wei, Y. Cai and Y. Yin, "A LowProfile Dual-Polarized Microstrip Antenna Array for DualMode OAM Applications," in IEEE Antennas and Wireless Propagation Letters, vol. 16, pp. 3022-3025, 2017, doi: 10.1109/LAWP.2017.2758520.

[26] H. H. Tran, N. Nguyen-Trong and H. C. Park, "A Compact Dual Circularly Polarized Antenna With Wideband Operation and High Isolation," in IEEE Access, vol. 8, pp. 182959182965, 2020, doi: 10.1109/ACCESS.2020.3022845.

[27] C. X. Mao, Y. Zhou, Y. Wu, H. Soewardiman, D. H. Werner and J. S. Jur, "Low-Profile Strip-Loaded Textile Antenna With Enhanced Bandwidth and Isolation for Full-Duplex Wearable Applications," in IEEE Transactions on Antennas and Propagation, vol. 68, no. 9, pp. 6527-6537, Sept. 2020, doi: 10.1109/TAP.2020.2989862.

[28] M. Ciydem and E. A. Miran, "Dual-Polarization Wideband Sub-6 GHz Suspended Patch Antenna for 5G Base Station," in IEEE Antennas and Wireless Propagation Letters, vol. 19, no. 7, pp. 1142-1146, July 2020, doi: 10.1109/LAWP.2020.2991967.

[29] Y.Lo, D. Solomon and W. Richards, "Theory and experiment on microstrip antennas," in IEEE Transactions on Antennas and Propagation, vol. 27, no. 2, pp. 137-145, March 1979, doi: 10.1109/TAP.1979.1142057.

[30] W. Richards and Y. Lo, "An improved theory for microstrip antennas and applications," 1979 Antennas and Propagation Society International Symposium, 1979, pp. 113-116, doi: 10.1109/APS.1979.1148165. 